\title{
O USO DA TERRA E AS IMPLICAÇÕES SÓCIO-AMBIENTAIS NA ZONA ÚMIDA DO RIO ARAGUAIA, ESTADO DE GOIÁS, BRASIL*
}

\author{
Alex Mota dos SAntos ${ }^{1}$
}

\begin{abstract}
Resumo - O rio Araguaia é um dos maiores do Brasil e sem dúvida o mais significativo para o estado de Goiás. Foi basicamente por este rio que os sertões do Brasil central foram desbravados. Da nascente até sua foz, a bacia é divida em Alto, Médio e Baixo Araguaia. Estes três segmentos apresentam paisagens bem distintas. $\mathrm{O}$ estudo que se apresenta está inserido no segmento do médio Araguaia, a partir do distrito de Registro do Araguaia, município de Montes Claros de Goiás, até a ponta sul da ilha do Bananal, no município de São Miguel do Araguaia. A área analisada ocupa cerca de $4430 \mathrm{~km}^{2}$ e é marcada pela presença de relevo plano, solos hidromórficos que, entre outras características, condicionam uma faixa não contínua de planície aluvial. A partir da década de 1960 a ocupação na área analisada é intensificada, especialmente pelos pecuaristas atraídos pelo baixo custo das terras, pelas políticas públicas de colonização e pelas características físicas da região. $\mathrm{O}$ artigo apresenta o cenário ambiental da zona úmida, a partir da interpretação de dados de sensoriamento remoto e visitas a campo para em seguida discutir os usos da terra e as implicações sócio-ambientais. A análise foi realizada para o ano de 2007 e revelou o desrespeito com a área úmida do rio Araguaia, reconhecida nacionalmente como de relevante interesse para preservação da natureza. Os resultados indicaram que $61 \%$ da área está comprometida com os usos para pecuária e agricultura sem distinção. A pecuária ocupa $42 \%$ da área de estudo, configurando atividade econômica predominante.
\end{abstract}

Palavras-chave: Uso da terra, implicações ambientais, áreas úmidas, Rio Araguaia, Brasil.

\begin{abstract}
LAND USE AND ITS SOCIO-ENVIRONMENTAL IMPLICATIONS IN THE WETLands of the Araguaia River (state of Goiás, BraziL). The Araguaia River is one of the largest in Brazil and certainly the most significant for the state of Goiás. It played a central role in the discovery of, and settlement in, the hinterlands of central Brazil. The Aruaguia river basin, in between its source and its mouth, is usually divided into three segments - High, Middle and Lower Araguaia - to which correspond different types of landscape. The present study focuses on a segment of the Middle Araguaia that
\end{abstract}

* Recebido: 8/08/2008. Revisto: 15/09/2008. Aceite: 3/11/2008.

1 Professor substituto da Coordenação de Geomática do Centro Federal de Educação Tecnológica de Goiás. E-mail: alexcefetgo@yahoo.com.br 
stretches from the Registro do Araguaia district (municipality of Montes Claros) to the southern tip of the Bananal island (municipality of São Miguel do Araguaia). The study area occupies an area of $4,430 \mathrm{~km}^{2}$ and is characterized by its smooth relief and hydromorphic soils, which are associated with a discontinuous strip of flood plain. Occupation of the study area intensified from the 1960s onwards, and was driven mostly by pastoralists who were attracted to the area by the low price of the land, the public policy of colonization and the physical characteristics of the region. This article presents an environmental characterisation of these wetlands, based on the interpretation of data acquired through remote sensing and a field work. It then discusses the predominant types of land use and their socio-environmental implications. The analysis refers to the year 2007 and indicates the existence of a number of serious threats to the integrity of the wetlands of the Araguaia River, whose relevance in terms of natural heritage has been acknowledged at the national level. In particular, the results show that $61 \%$ of the study area is allocated to either cattle farming or agriculture, and that the predominant economic activity, cattle farming, takes up $42 \%$ of that area.

Key words: Land use, environmental implications, wetland, Araguaia River, Brazil.

Résumés - L'UTILISATION DU SOL ET SES IMPLICATIONS SOCIO-ENVIRONNEMENTALES, DANS la zONE humide du Rio Araguaia (Goias, Bresil). Le Rio Araguaia est un des plus importants du Brésil et la mise en valeur de l'intérieur du Brésil central s'est principalement faite au long de son cours. Les paysages des cours supérieur, moyen et inférieur sont fort différents. On considère ici le cours moyen, depuis le district de Registo do Araguaia (Montes Claros de Goiás) jusqu'à l'extrémité sud de la grande île du Bananal (São Miguel do Araguaia). Sur environ $4430 \mathrm{~km} 2$, le relief est plat et des sols hydromorphes caractérisent une bande discontinue de plaine alluviale. Depuis 1960, l'occupation s'est intensifiée, surtout de la part d'éleveurs, attirés par le bas coût des terres, la politique de colonisation et les caractéristiques régionales. On caractérise le milieu de la zone humide, en se basant sur des données de télédétection et des visites de terrain et on discute ensuite de l'utilisation du sol et de ses implications, sociales et environnementales. L'analyse, réalisée en 2007, a révélé que la zone humide de l'Araguaia n'a pas été respectée, alors qu'elle est considérée, au niveau national, comme d'exceptionnel intérêt pour la préservation de la Nature. L'agriculture et l'élevage affectent $61 \%$ de l'aire considérée, dont $42 \%$ pour le seul élevage.

Mots-clés: Utilisation du sol, implications environnementales, zone humide, Rio Araguaia, Brésil.

\section{INTRODUÇÃO}

Há consenso entre historiadores em afirmar que o Rio Araguaia configurou importante elemento de integração entre o colonizador e os sertões do Brasil central. Atualmente no Brasil o nome Araguaia, arara de calda longa, na língua indígena, referencia comércios, livros, filmes, avenidas e cidades.

Apesar da presença de inúmeras tribos indígenas ferozes nas suas margens, o rio Araguaia permitiu que os colonizadores alcançassem terras distantes do oeste brasileiro. Pelas águas do Araguaia passaram homens destemidos que abriram caminho para a 
colonização de parte do território nacional. Essas viagens contribuíram para um vasto conhecimento acerca da fauna e flora que envolve o Rio Araguaia, contribuindo assim para chamar a atenção do país para esta região. Talvez o fato mais marcante tenha sido a descoberta do ouro em alguns tributários do Rio Araguaia, motivo das principais movimentações pela região.

Após o período de corrida ao ouro, a pecuária foi a atividade econômica que mais se desenvolveu, aproveitando especialmente a vasta área de pastagens naturais encontradas nas áreas úmidas da planície de inundação. Com a consolidação da pecuária, que ocorreu a partir da década de 1960, abriram novas fazendas que se dedicaram à pecuária intensiva, através da retirada da vegetação natural e do cultivo das pastagens com gramíneas exóticas, isso porque a gramínea exótica é mais resistente às condições de baixa precipitação. Os fazendeiros que aportaram na região tiveram apoio através das políticas públicas dos governos federal e estadual, através do Programa de Desenvolvimento Integrado da Bacia Araguaia-Tocantins (PRODIAT), que incentivou a construção de estradas, interligando a região dos sertões araguaianos na malha viária de Goiás e do Brasil.

No período atual, reflexo dos movimentos históricos, a paisagem das zonas úmidas encontra-se bastante alterada, fato discutido neste artigo. Nesta conversão identificou-se o predomínio dos usos para pecuária e agricultura convencional, especialmente para cultivo de milho, arroz e soja.

\section{ZONAS ÚMIDAS E ÁREA DE ESTUDO}

A discussão em torno das zonas úmidas foi ratificada na década de 1970, quando se realizou, no Irã, a Convenção de Ramsar. Este evento deu origem a um tratado de cooperação entre as nações do mundo, visando a conservação das zonas úmidas. A convenção de Ramsar definiu zonas úmidas como pântanos, charcos, turfas e corpos de água, naturais ou artificiais, permanentes ou temporários, com água estagnada ou corrente, doce, salobra ou salgada, incluindo estuários, planícies inundáveis, ilhas e áreas marinhas costeiras (BRASIL, 2006). Em todo o mundo são quase 800 áreas já determinadas pela convenção de Ramsar (WWF-BRASIL, 1996).

A partir de 1993 o Brasil tornou-se signatário da Convenção de Ramsar, designando cinco áreas a serem incluídas na lista de zonas úmidas de interesse internacional. São elas: Lagoa do Peixe, no Rio Grande do Sul; Mamirauá, no Amazonas; Pantanal, no Mato Grosso e Mato Grosso do Sul; Reentrâncias Maranhenses, no Maranhão e a Ilha do Bananal, no Tocantins (BRASIL, 2006). A área analisada está localizada nas proximidades, a cerca de 2 quilômetros da Ilha do Bananal. Segundo o tratado foi definido o dia 2 de Fevereiro como o Dia Mundial das Zonas Úmidas. Para 2007 o tema central das discussões foi a pesca e seus impactos. As zonas úmidas são quase tão antigas quanto o próprio planeta, e abrigam uma das áreas mais ricas da biodiversidade da Terra (WWF-BRASIL, 1996).

A área de estudo está localizada no domínio do Cerrado. Este bioma, que apresenta grande variedade de espécies da fauna e flora, é um dos mais ricos do mundo e um dos mais ameaçados pela ação humana, especialmente pela atividade agropecuária. O Cerrado apresenta grande heterogeneidade de ambientes que está relacionada com o clima, a pedologia e as formas do relevo. Neste bioma são encontradas vastas áreas úmidas, especialmente aquelas associadas às planícies de inundação dos grandes rios e as veredas. Estas últimas representam pequenas áreas e são encontradas de forma isolada. Ambas são caracterizadas pela presença de solos hidromórficos e flora que se adaptaram 
as condições de forte umidade destes solos. Na parte oeste do estado de Goiás encontrase um dos maiores rios do país, o Araguaia, que juntamente com seus tributários formam a maior área de inundação do estado de Goiás.

A área de estudo abrange seis municípios e localiza-se no extremo Oeste do estado de Goiás, na divisa com o estado de Mato Grosso (fig. 1), na região Centro-Oeste do Brasil. Toda a área é banhada pelo Rio Araguaia. As paisagens cortadas por esse rio apresentam características bem distintas, onde se destaca a presença de áreas de inundações anuais. Estas apresentam rica fauna e flora, muito semelhante às do Pantanal Mato-Grossense e Floresta Amazônica.

A vegetação que ainda se encontra na área de estudo serve de proteção para o desenvolvimento de animais silvestres de grande porte, como a anta e a onça. Identificou-se na área de estudo a presença da Floresta Semidecidual Aluvial e a Savana Parque com Floresta de Galeria. Nesta última desenvolvem-se os murundus ou monchões ${ }^{2}$ de diferentes alturas e tamanhos. A vegetação sobre os murundus apresenta porte arbóreo, pois normalmente não é atingida pelas cheias do Rio Araguaia. Entre os murundus, onde a inundação ocorre, identificou-se a presença de vegetação graminosa, fonte de alimento para o gado bovino.

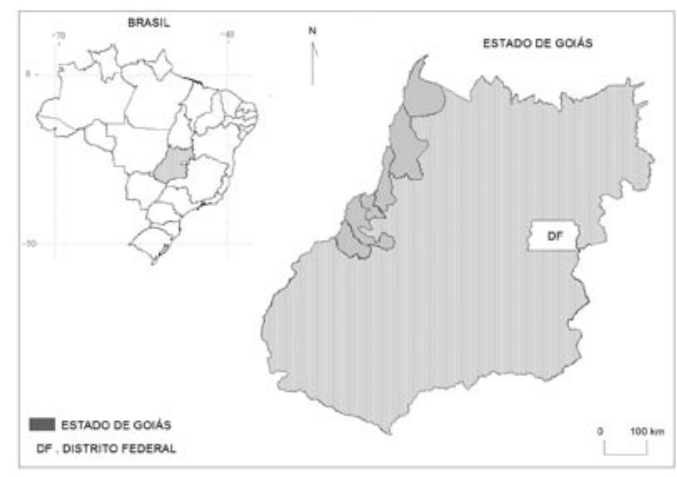

Fig. 1 - Localização da área de estudo

Fig. 1- Location of the study area

As características desta parte do Cerrado são condicionadas por diversos elementos, dos quais se destacam a pedologia, predominando os solos do tipo hidromórficos, com destaque para os gleissolos; pela geomorfologia, caracterizada pela presença da Planície do Araguaia, na qual se distinguem duas formas de relevo: a Área de Acumulação Inundável e a Área de Planície Fluvial, que resultam na formação de relevo extremamente plano; quanto ao clima, apresenta dois períodos bem definidos: período seco, que ocorre entre Abril e Setembro, e período chuvoso que se estende de Outubro a Março. Da margem direita, estado de Goiás, o Rio Araguaia despeja todos os anos grande quantidade de água proveniente do seu pulso máximo de inundação, caracterizada neste artigo como zona úmida e que ocupa cerca de $4430 \mathrm{~km}^{2}$. A paisagem de inunda-

2 Tipo de micro relevo peculiar onde se desenvolvem pequenos montes, de 3 a 15 metros de diâmetro e cuja altura não excede 3 metros. Acredita-se que os murundus da área de estudo estão associados às condições de má drenagem. 
ção é de extrema importância para o equilíbrio da fauna e flora, já que oferece condições favoráveis à reprodução e sobrevivência de inúmeras espécies.

No período de seca formam-se lagos sazonais que compõem uma paisagem com cerca de 507 ambientes aquáticos. A inundação atinge os municípios goianos de São Miguel do Araguaia, Nova Crixás, Aruanã, Britânia, Jussara e Montes Claros de Goiás; no entanto, é mais expressiva na região norte da área de estudo, no município de São Miguel do Araguaia. Cerca de 30\% (1 $\left.800 \mathrm{~km}^{2}\right)$ do município de São Miguel do Araguaia fica submerso no período de enchente máxima. Esta área é representativa, pois São Miguel é um dos maiores municípios do Estado de Goiás.

A relevância da área de estudo foi destacada no levantamento nacional das áreas prioritárias para a conservação da natureza. Em Goiás, o WWF-Brasil, o Ministério do Meio Ambiente e a Agência Goiana do Meio Ambiente, a partir de financiamento do Banco Mundial, destacaram 400 áreas como relevantes para a conservação dos recursos naturais no estado. Destas, três áreas encontram-se na região de estudo (fig. 2).

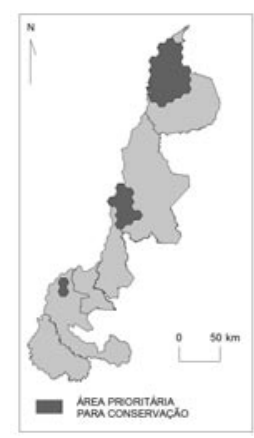

Fig. 2 - Áreas prioritárias para conservação da natureza na área de estudo

Fig. 2 - Priority areas for nature conservation in the study area

O projeto de definição de áreas prioritárias incentivou o estado de Goiás a duplicar a área de unidades de conservação. O levantamento foi entregue à Agência Goiana do Meio Ambiente, que tem a responsabilidade de criar políticas de conservação destas áreas. A maior área indicada para conservação encontra-se no município de São Miguel do Araguaia, seguida do município de Nova Crixás e Aruanã. Estas áreas apresentam ainda rica fauna e flora. No entanto, o descuido do poder público tem contribuído para que os usos ocorram indiscriminadamente e a indicação de área prioritária fique somente nos documentos oficiais dos órgãos ambientais.

\section{PROCEDIMENTOS METODOLÓGICOS}

\section{Análise da paisagem}

Descortinar o meio para avaliar suas potencialidades tem sido tarefa incansável do homem, fato que acompanha sua história na Terra. A partir do século XX, com a inserção das Tecnologias de Informação Geográfica sua busca tem sido facilitada e realizada à distância, especialmente com o advento das imagens obtidas por aviões, plataformas 
suborbitais, ou mesmo por satélites, plataforma orbital. A análise tem sido eficaz devido ao amplo campo de abrangência dos sensores a bordo dos satélites, fato que tem revelado o planeta Terra de forma fidedigna e passível de interpretação.

Atualmente a busca pela análise da paisagem deixou de ser realizada apenas com o intuito de reconhecer o meio, passando a incidir também na apropriação do mesmo. As análises têm se direcionado para verificar os vestígios deixados pelo homem, bem como as conseqüências adversas para a sobrevivência de inúmeras espécies da fauna e flora, que simplesmente tendem a desaparecer. No final do século XX e início do século XXI a disseminação dos produtos de sensoriamento remoto, muitas vezes a custo zero, tem contribuído para revelar um meio ambiente agredido e muitas vezes impactado. As pesquisas têm sido de grande valia para a tomada de decisão por parte dos gestores públicos.

Neste sentido, a parceria Brasil e China possibilitou desenvolver o Satélite Sinobrasileiro de Recursos Terrestres (CBERS), que possui sensores capazes de oferecer alto poder de detalhamento da paisagem. Este artigo foi realizado a partir dos produtos de sensoriamento remoto obtidos pelo satélite CBERS disponibilizados pelo Instituto Nacional de Pesquisas Espaciais (INPE). O satélite CBERS-2 foi lançado pelo governo brasileiro no ano de 2003. As imagens utilizadas são aquelas tomadas pela Câmera Imageadora de Alta Resolução (CCD), instalada no satélite CBERS-2. Além da câmara CCD, o satélite CBERS possui mais dois sensores: o IRMSS (Infrared Multispectral Scanner), resoluções de 80 e 160 metros e WFI (Wide Field Imager), resolução de 260 metros (INPE, 2007). O sensor CCD é a única câmara, deste satélite, que apresenta condições de resolução espacial, 20 metros, compatível com a análise proposta. De forma geral, a resolução espacial vai indicar o poder de detalhamento dos alvos na imagem. Este nível de precisão está relacionado tanto com as características do sensor quanto dos alvos. A Câmera CCD opera em cinco faixas espectrais, que vão do visível (comprimento de onda de $450 \mathrm{~nm}^{3}$ a $690 \mathrm{~nm}$ ), passando pela banda pancromática (comprimento de onda 510 a $730 \mathrm{~nm}$ ), até uma banda no infravermelho próximo, que opera entre as faixas 770 a $890 \mathrm{~nm}$. Do sensor CCD selecionaram-se as bandas 2, 3 e 4. Essas bandas respondem, respectivamente, nos comprimentos de onda do verde, vermelho e infra-vermelho próximo. A escolha dessas bandas é justificada pela aplicação de cada uma delas, apresentada no quadro I.

Quadro I - Características das bandas do Sensor CCD do satélite CBERS-2 e respectivas aplicações

Table I - Characteristics of the bands of the CCD Sensor of the CBERS-2 satellite and respective applications

\begin{tabular}{lrl}
\hline Banda & $\begin{array}{r}\text { Intervalo } \\
\text { Espectral }\end{array}$ & \multicolumn{1}{c}{ Aplicação na área de estudo } \\
\hline 2 & $520-590 \mathrm{~nm}$ & $\begin{array}{l}\text { Identificação, discriminação e delineamento entre solo exposto e outros alvos. } \\
\text { Identificação de estradas. }\end{array}$ \\
3 & $630-690 \mathrm{~nm}$ & $\begin{array}{l}\text { Discriminação entre os diversos tipos vegetacionais. } \\
\text { Delineamento e discriminação entre corpos d'água e solo/vegetação. }\end{array}$ \\
\hline
\end{tabular}

Adaptado de Moreira (2001)

3 nm - nanômetro: unidade de medida dos comprimentos de ondas das bandas espectrais. 
As bandas espectrais, quando associadas ao espaço de cores RGB, possibilitam uma composição de cores que facilita a análise ambiental. Neste sentido, para estudo detalhado do aspecto da cobertura vegetal e usos da terra estabeleceu-se a composição R (3) G (4) e B (2). Segundo Moreira (2001), a finalidade desse procedimento é aumentar a acuidade do sistema visual humano em discernir diferentes feições na imagem, durante a fase de classificação. Esse procedimento resulta na composição falsa cor, a que mais representa o real no que diz respeito ao detalhamento das cores dos alvos. A vegetação assume a cor verde, variando do verde escuro, para vegetação densa, ao verde claro, para vegetação rala; o solo se apresenta em tons róseos e a água representa-se pela cor azul e pelo preto.

Devido à extensão da área de estudo foi necessário mais de uma cena. Desta forma utilizaram-se imagens CBERS das órbitas 160 e 161 do mês de Setembro e Agosto, respectivamente. Das cenas selecionaram-se os pontos 114 e 115 para a órbita 160 e 114, 115, 116, 117 e 118, da órbita 161.

As cenas foram mosaicadas em ambiente de Sistema de Informação Geográfica (SIG), bem como todo o processo de manipulação e integração dos dados espaciais. Para esta tarefa utilizou-se o Sistema de Processamento de Informações Georreferenciadas (SPRING), versão 4.3.3.

\section{Determinação dos usos e cobertura da terra}

O uso da terra envolve o manejo empregado e a estrutura de produção (relações sociais de produção). Nesta pesquisa utilizaram-se as classes definidas pelo Instituto Brasileiro de Geografia e Estatística - IBGE. A metodologia do IBGE hierarquiza os usos da terra em 3 níveis: Nível I (classes), Nível II (subclasses) e Nível III (unidades). Esses níveis estão relacionados com a escala de análise. O nível I atende a usuários interessados nas escalas de análise nacional ou inter-regional, o nível II responde aos interesses na escala de análise regional e o nível III é sobretudo dirigido aos interessados em análise local. Na análise de nível III recomenda-se visita de campo, inventários e entrevistas, como etapas complementares da elaboração do mapea-mento (IBGE, 2006).

\section{Determinação da zona úmida}

A zona úmida (fig. 3) foi identificada a partir da interpretação visual das imagens orbitais do período de alta precipitação. Para as cenas comprometidas por nuvens utilizaram-se dados da Secretaria Estadual de Planejamento do Estado de Goiás - SEPLANGO - através do Sistema de Informações Estatística e Geográfica.

\section{RESULTADOS}

\section{Usos mais recorrentes nas áreas úmidas}

De acordo com a metodologia utilizada identificaram-se as seguintes classes de uso (fig. 4): núcleos urbanos, incluídos na subclasse áreas urbanizadas, Projeto de Irrigação, Agricultura mecanizada com presença de pivô, Pecuária de corte, Agricultura, Vegetação Florestal, Ilhas e Bancos de areia, Parque Estadual do Araguaia e Floresta Estadual. As áreas urbanas são áreas de uso intensivo, estruturado por edificações e sistema viário, onde predominam as superfícies artificiais não-agrícolas. 


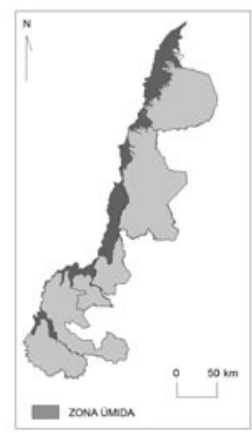

Fig. 3 - Zona úmida do Rio Araguaia no Estado de Goiás Fig. 3 - Araguaia River Wetlands, State of Goiás

No quadro II observa-se a síntese dos usos da terra.

Quadro II - Análise quantitativa dos usos e cobertura da terra Table II - Quantitative analysis of landuse and landcover

\begin{tabular}{|c|c|c|}
\hline Uso e Cobertura & Área $\left(\mathrm{km}^{2}\right)$ & \% da Área Total \\
\hline Projeto de Irrigação & 33,00 & 0,75 \\
\hline Agricultura Mecanizada - Pivô & 8,72 & 0,19 \\
\hline Agricultura sem distinção & 841,70 & 19,0 \\
\hline Ilhas e Bancos de Areia & 15,56 & 0,35 \\
\hline Parque Estadual do Araguaia & 46,11 & 1,04 \\
\hline APA Meandros do Araguaia & 68,69 & 1,55 \\
\hline Vegetação de Floresta & 797,39 & 18,0 \\
\hline $\operatorname{Lagos}^{4}$ & 31,42 & 0,71 \\
\hline Pecuária & 1860,60 & 42,0 \\
\hline
\end{tabular}

Observa-se que a Pecuária representa 42\% e Agricultura sem distinção com 19\% dos usos da terra identificados na área de estudo, confirmando a vocação da região para a atividade agropecuária. A vegetação de Floresta cobre $18 \%$ da área de estudo, no entanto a sua expressiva ocorrência está comprometida pelos usos que ocorrem no seu interior.

\section{IMPLICAÇÕES SÓCIO-AMBIENTAIS}

O avanço da agropecuária sobre as paisagens da zona úmida do Rio Araguaia, intensificada a partir do século XX, tem contribuído para alterar o arranjo espacial dos

4 A partir das imagens de sensoriamento remoto foi possível identificar mais de 500 lagos na zona úmida. 
elementos bióticos e abióticos. Tal alteração compromete a vegetação natural (ver quadro II), mas são a fauna e o rio Araguaia os mais agredidos pelas ações antrópicas.

A pecuária se desenvolveu, deixou de ser rudimentar, para ser "moderna". O boi supervalorizado nessas paisagens determina um novo período para a economia regional. Atualmente, a pecuária assenta em bases ainda mais modernas, incorporando a inseminação artificial, que garante um boi mais robusto, com maior ganho de peso num curto espaço de tempo. O boi "pé duro"5, como se referia o pioneiro, outrora considerado de qualidade, não satisfaz a necessidade do mercado da carne, que exige cada vez mais rendimento dos rebanhos. Esta alteração na pecuária foi subsidiada em parte pelo Estado, a partir do Decreto n. ${ }^{\circ} 4$ 579, de 20 de Outubro de 1995, que instituiu o Projeto Novilho Precoce, com o objetivo de estimular os pecuaristas do Estado de Goiás à criação e ao desenvolvimento de animais que possam ser abatidos precocemente.

Segundo dados do IBGE, os municípios da área de estudo possuíam 2215555 cabeças de gado bovino no ano de 2006, um número aproximadamente 22 vezes maior que o de pessoas que lá vivem. Ao calcular este número em relação à área de todos os municípios, tem-se na área de estudo cerca de 90 bois por $\mathrm{km}^{2}$. Esta quantidade impressiona e reforça a tese de que a área de estudo apresenta vocação econômica no período atual para a pecuária.

Fazendo análise multitemporal do quantitativo bovino (fig. 4) observou-se que apenas um município, Montes Claros de Goiás, apresentou decréscimo de gado vacum. Este decréscimo é explicado pelo aumento na área de cultivo para agricultura.

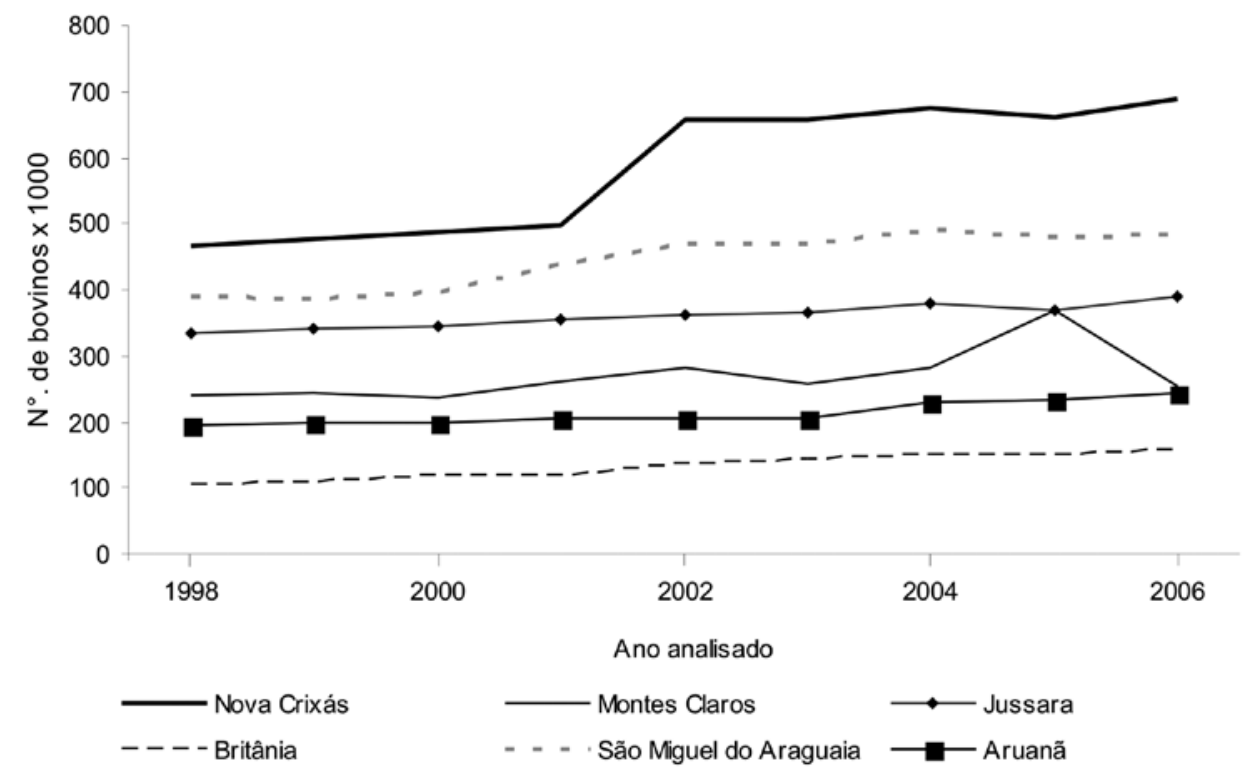

Fonte: IBGE (2007) e Secretaria Estadual de Planejamento de Goiás - SEPLAN-GO (2007).

Fig. 4 - Crescimento do quantitativo bovino nos municípios da área de estudo Fig. 4 - Growth of cattle in the municipalities within the study area

5 "Boi pé duro", também chamado de curraleiro, é o animal sem raça definida, criado a solta, boi bravo, catingueiro de difícil manuseio. 
No final do século XX e início do século XXI a cana-de-açúcar começa a ser cultivada na área de estudo. Segundo dados da SEPLAN-GO, no ano de 2000 apenas o município de Aruanã possuía cultivo de cana-de-açúcar. Para o ano de 2006 somente o município de Britânia não apresentava área de cultivo para este produto. Ainda segundo dados da SEPLAN-GO a área cultivada com cana-de-açúcar cresceu 125 vezes no município de Montes Claros de Goiás, entre os anos de 2002 e 2006. Entre os anos de 2001 e 2006, a área cultivada no município de Jussara cresceu 59 vezes. O crescimento da população das sedes dos municípios manteve-se estável, não ultrapassando $2 \%$. Destaca-se que todos os municípios têm sua população vivendo predominantemente nas cidades. Estes dados revelam que a agricultura nos moldes atuais oferece poucos postos de trabalho no campo.

Outro ponto de discussão diz respeito aos inúmeros núcleos urbanos localizados na área de inundação. Todos eles estão localizados nas margens do Rio Araguaia e têm sua história de origem ligada ao período de navegação por este rio. Muitos destes lugares surgiram a partir das paragens dos colonizadores que circulavam pela região. Por estarem na zona inundação, todos os núcleos urbanos sofrem no período de cheia máxima, pois são atingidos pelas águas do Rio Araguaia, sendo necessário a intervenção do governo para apoio às pessoas desabrigadas. Tal fato é mais recorrente nos primeiros meses de cada ano (Janeiro e Fevereiro), quando as águas do rio atingem cotas altíssimas.

Em Luiz Alves, um dos maiores distritos da área de estudo, muitos moradores se lembram da enchente do início da década de 1980, quando muitas casas foram destruídas e animais domésticos morreram. No ano de 2007 as águas do Rio Araguaia atingiram 7,46 m, quase a cota de alerta que, para a área, é de 8 metros (Arruda, 2007). Mesmo abaixo da cota de alerta a enchente causou transtornos, pois algumas famílias de Luiz Alves sofreram e necessitaram do auxílio da defesa civil.

O medo das enchentes é eminente, mas o apego ao lugar é fato curioso. A relação do ribeirinho com o Rio Araguaia é notória nas conversas onde os mesmos constroem uma imagem do rio como o protetor, aquele de onde tudo provém.

A maioria dos pequenos núcleos urbanos vive em função do rio, que é um dos mais piscosos do Brasil. O turismo ajuda a economia local, pois muitas pessoas se deslocam até aí, vindo dos municípios vizinhos, do estado de Mato Grosso e Goiás, também de outros estados e até mesmo de outros países.

Neste contexto, o núcleo mais desenvolvido é a cidade de Aruanã. Esta cidade se torna a porta de entrada do Vale do Rio Araguaia, já que o acesso a cidade é mais facilitado, em função da infra-estrutura viária presente, rodovia pavimentada, que é integrada na malha viária do Estado de Goiás. Segundo dados da prefeitura de Aruanã cerca de 150 mil pessoas buscam Aruanã todos os anos. A partir desta cidade os turistas se dispersam para outros distritos às margens do rio Araguaia. Os demais núcleos atraem os turistas mais aventureiros, aqueles que gostam de acampar às margens do rio.

O distrito de Luiz Alves, outro importante roteiro turístico apresenta estrutura hoteleira básica com comércio, posto de gasolina e barcos hotéis. Os barcos hotéis percorrem o rio e oferecem um turismo de aventura. Muitas pessoas que se deslocam pelo rio estão interessadas na pesca, sendo comum apreensões de muitos quilos de pescados todos os anos.

No contexto é possível identificar todos os núcleos urbanos da área de estudo. Neste sentido, identifica-se primeiramente o distrito de Registro do Araguaia, localizado no município de Montes Claros de Goiás. Neste distrito é comum a instalação de casas de passeio por parte do turista que se desloca até Registro nos períodos de férias escolares 
(meses de Julho e Dezembro) e feriados prolongados. Após Registro do Araguaia identifica-se Itacaiu, localizado no município de Britânia. Os demais povoados, Peixe, Xixá, os Condomínios, Bemvinda e Fio Velasco apresentam vida urbana modesta, com poucos moradores e comércio de subsistência. Muitos destes moradores são oriundos da capital federal, Brasília. Os condomínios são formas de ocupação que tem aumentado ao longo dos anos nas margens do rio Araguaia e de seus tributários. Segundo Souza et al. (2002) ir ao Araguaia é motivo de status. Ter uma segunda residência às margens deste majestoso rio é motivo para se fazer grandes investimentos. Todos os condomínios desrespeitam as leis ambientais, pois estão instalados na Área de Preservação Permanente (APP) ${ }^{6}$.

As alterações do cenário ambiental da área de estudo são agravadas pelo projeto de irrigação Luiz Alves do Araguaia. Este projeto gerou implicações sócio-ambeintais, pois ampliou a área de desmatamento da vegetação remanescente e contribuiu para a marginalização da população local, pois atraiu muitas pessoas que não retiraram do projeto o sustento necessário para suas famílias.

Segundo Sgreccia (2006) o projeto de irrigação segrega a população local, desqualificada economicamente, pelas regras impostas pelos editais de concorrência. "O povão continua a ser apenas a mão-de-obra barata de gaúchos, mineiros e outros apadrinhados políticos". Esta atividade gerou danos ambientais sem precedentes, pois desviou o fluxo de inundação, alterou nascentes de algumas drenagens e suprimiu a vegetação natural da área inundável. Este projeto está dividido em etapas, sendo que somente a Etapa 1 está em funcionamento, com muitos lotes improdutivos. Segundo alguns proprietários, a improdutividade está relacionada com ao alto custo do cultivo da terra.

Num primeiro momento o projeto de irrigação, que consumiu 15,8 milhões de reais, contribuiu para que muitos trabalhadores buscassem a região de Luiz Alves com objetivo de melhorias nas condições de vida. O tal sonhado desenvolvimento durou pouco, já que a dificuldade de acesso ao local, falta de apoio na forma de subsídios e o alto custo dos suprimentos agrícolas contribuíram para que muitos arrendatários desistissem dos seus lotes.

O verdadeiro abandono do Projeto de Irrigação leva a conclusão de que a obra não foi benéfica para a população local e o passivo ambiental é gigantesco. Apesar da produção e comercialização dos produtos por parte de alguns poucos arrendatários, o que se viu no Projeto de Irrigação, no ano de 2007, foi a existência de grandes áreas abandonadas. O projeto de irrigação configura a única área de agricultura na parte norte da área de estudo.

$\mathrm{Na}$ parte sul existe vasta área de cultivo agrícola. Em alguns pontos o solo exposto revela o preparo para receber o plantio. Segundo dados do IBGE, o município de Montes Claros de Goiás, extremo sul da área de estudo, é aquele que apresenta maior área de lavoura. Nesta região a pecuária está perdendo espaço para a cana-de-açúcar, que figura no cenário mundial como "atividade econômica da vez" devido sua utilização na produção dos biocombustíveis. Em 2007 existiam em Goiás 15 usinas sucroalcooleira e isto o colocava como o quinto maior estado canavieiro do Brasil. Até o final de 2008 mais 17 usinas estarão em funcionamento (SEPLAN, 2007). Além do cultivo para a cana, a soja também apresentou aumento expressivo da área cultivada.

6 Faixa marginal ao rio, medida a partir do nível mais alto, em projeção horizontal, com largura que depende também da largura do curso de água. Se os cursos de água são mais largos, mais extensa será a APP. 
Analisando a agricultura de grãos, segundo dados da SEPLAN-GO, apenas o município de São Miguel do Araguaia não apresentou crescimento na produção entre os anos de 2004 e 2006. Isto revela que, ao contrário da parte norte da área de estudo, a do sul é predominantemente agrícola.

Os reflexos negativos das atividades identificadas na área de estudo são facilmente percebidos. O Rio Araguaia sofre com o aumento de sedimentos provenientes de erosões causadas pelo desmatamento e manejo inadequado do solo, que ocorre especialmente nas áreas de relevo mais movimentado, nas bordas da planície e nas nascentes do Rio Araguaia, região sul da área de estudo. Segundo Santos e Romão (2007) o desflorestamento em parte da área de estudo, entre os anos de 1960 a 2007 foi de 14\%. No contexto do estado de Goiás, conforme levantamento da Secretaria Estadual do Meio Ambiente e Recursos Hídricos apresentado por Santos (2007), mais da metade dos municípios possuem menos de $20 \%$ da vegetação natural preservada. Entre a década de 1960 e 1990 o desmatamento foi realizado predominantemente para a formação de pastagens plantadas (fig. 5), que teve aumento considerável no período analisado.

O desmatamento na área de estudo não é contínuo, já que avança de forma irregular e em pontos distintos. Em algumas áreas os proprietários deixam fragmentos vegetacionais no meio dos pastos. Esse tipo de preservação não é eficaz, já que obriga a fauna a se dispersar pela área de uso intenso, ficando assim exposta a agressão humana.

Apesar da vasta área de floresta, mesmo fragmentada, foi possível presenciar, a partir de visitas a campo, que a interferência humana ocorre no interior das florestas, inclusive para criação de gado bovino. Verdadeiros caminhos são abertos no interior da vegetação.

Outra questão relacionada a pecuária está no fato de que as fezes do gado bovino podem contribuir para a eutrofização dos ambientes lacustres, já que a enxurrada leva as fezes para os lagos, o que contribui para o acúmulo de matéria orgânica nos ambientes aquáticos. Tal processo pode favorecer o aumento de plantas aquáticas, que compromete a qualidade da água e das espécies da ictiofauna.

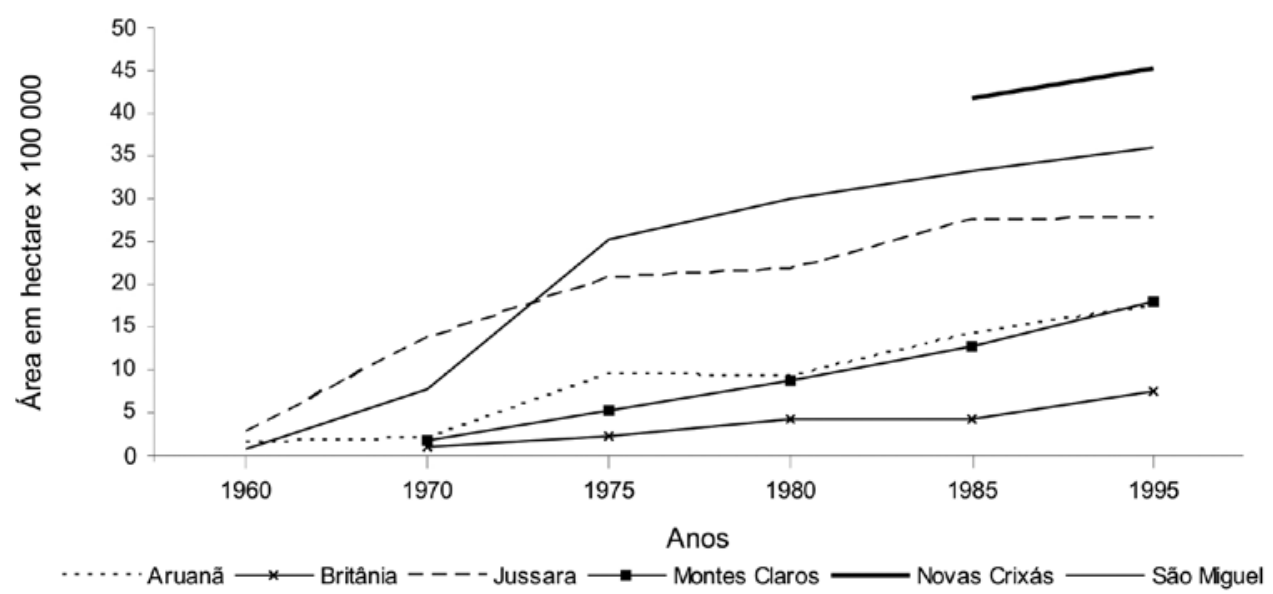

Fonte: Instituto de Pesquisa Econômica e Aplicada - IPEA (2007).

Fig. 5 - Evolução da área de pastagem

Fig. 5-Development in the area of grassland 
Neste sentido, Castro (2005) apresentou análise da aptidão agrícola nas áreas da alta bacia do Rio Araguaia e constatou desrespeito e manejo inadequado em áreas de declives mais acentuados, o que contribui para a ocorrência de erosões. Castro (2005) afirma ainda que os usos inadequados, materializados nos elementos como trilhas deixadas pelo gado bovino, cercas e valas de divisa transversais às curvas de nível e mesmo os terraços mal dimensionados são elementos responsáveis pela identificação de inúmeras voçorocas, um tipo de erosão que já atingiu o lençol freático.

Os sedimentos provenientes das erosões e voçorocas nas áreas mais altas atingem o leito do rio e condicionam o aumento no surgimento dos bancos de areia indicados pela cor branca na (fig. 6). Estes sedimentos contribuem para o alargamento e conseqüente diminuição da profundidade do rio, influenciando negativamente a navegação, especialmente nos períodos de baixa precipitação.

Quando da visita a campo foi possível perceber que os bancos de areia causam transtornos e oferecem perigo aos navegantes, pois as embarcações encalham na areia.

Segundo Morais (2006) a atividade lateral do canal também é alta, sendo registrados valores de erosão superiores a $10 \mathrm{~m}$ por ano. Segundo dados do Projeto Fluxo de Sedimentos na Bacia do Araguaia-Tocantins, (Lima et al., 2003), a região de planície é parte da bacia do Rio Araguaia que apresenta maior concentração de sedimentos: mais de $300 \mathrm{mg} / \mathrm{l}$.

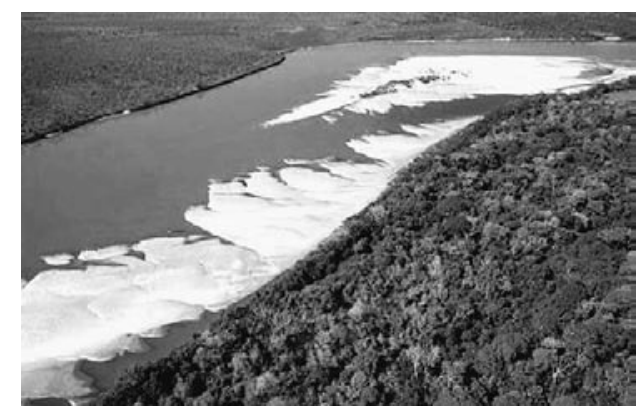

Foto de Tropical Turismo.

Fig. 6 - Bancos de areia no Rio Araguaia

Fig. 6 - Banks of sand in the Araguaia River

A fauna também é ameaçada, e em muito diminuída, sendo elemento da paisagem que merece destaque. As poucas pesquisas sobre a fauna do Rio Araguaia privilegiam aspectos genéticos e de distribuição das espécies. Não se tem uma análise sobre o índice de comprometimento da fauna. Assim, a diminuição das espécies pode ser percebida em visitas a campo. No início da década de 1990, quando dos passeios pela área de estudo, era possível identificar grande variedade da fauna. Neste período observavam-se até restrições a algumas áreas, pelo perigo eminente de ataques às pessoas.

Uma das espécies da fauna mais atingida pela ocupação da área de estudo é sem dúvida o belo peixe Pirarucu (Arapaima gigas). A diminuição desta espécie levou o órgão ambiental do Estado de Goiás, a proibir, via Lei 13 025/97, a pesca deste animal em território goiano (Santos, 2007). O Pirarucu é considerado o maior peixe de escamas de água doce do mundo (Pereira, 1976). Este peixe tem sua reprodução afetada pelos usos 
da terra, já que a área está bastante exposta e o gado bovino que se descedenta nas margens dos lagos afugenta o gigante de escamas, que busca justamente estes locais para se reproduzir. Santos (2007) fez uma análise das notícias oficiais vinculadas no Estado de Goiás e revelou que foram apreendidas 3,1 toneladas da carne do Pirarucu, somente no ano de 2005. Do peixe Pirarucu não se aproveita apenas a carne, pois suas escamas são utilizadas na confecção de bijuterias e roupas. Bijuterias confeccionadas com escamas de Pirarucu são comercializadas em praticamente todos os estados brasileiros e também na Europa.

Além das agressões ambientais, conflitos sociais pela posse da terra foram também identificadas na área de estudo. Ao longo do Rio Araguaia é possível observar inúmeros pontos de invasões por parte do Movimento dos Sem-Terra (MST). Os grileiros constroem suas moradias precárias na beira do barranco, onde ocorre criação de porcos e plantio de bananas.

O crescimento dos movimentos de grilagem de terra pode ser explicado pela alta concentração da terra na área de estudo. Em municípios como Aruanã, o aumento da concentração da terra foi de 28,09\% e em Jussara de 55\%, entre 1970 e 1990 (IPEA, 2007). Num período curto os pequenos proprietários foram “expulsos” pelo latifúndio. São Miguel do Araguaia é o único município onde a concentração da terra foi considerada muito baixa. Isto pode ser explicado porque os movimentos dos sem-terra neste município estão organizados e realizam invasões continuamente. Foi possível identificar que as invasões ocorrem principalmente nas fazendas que encontram dificuldades financeiras para manutenção das atividades agropecuárias. Neste sentido, observa-se que o dinheiro do governo para a indenização das terras invadidas é sempre bem vindo por parte do proprietário.

No ano de 2002 uma grande invasão do MST ocorreu na parte central da área de estudo. O Estado se mobilizou em defesa do empresário e destinou 3 mil policiais para retirar os 3,4 mil integrantes do MST (Leobas, 2002), ou seja, foi praticamente um policial para cada invasor do MST, considerando a presença de crianças e mulheres. Para defender o interesse do empresariado o Estado se mostrou muito eficaz, como deve ser, fato não percebido quando se trata de defender os interesses da coletividade, fazendo-se cumprir as leis ambientais que, em Goiás como no Brasil, são muito bem elaboradas, mas pouco aplicadas.

Em função das características singulares de riqueza biológica, identificaram-se na área de estudo tentativas de conservação da natureza a partir da criação de Unidades de Conservação (UC). Neste sentido, há uma UC de Proteção Integral, onde segundo a Lei Ambiental do Brasil o uso é proibido. Esta UC é representada pelo Parque Estadual do Araguaia que, conforme análise empírica, apresenta tráfego livre aos bovinos e pescadores. As terras desapropriadas para o parque do Araguaia não foram pagas pelo Estado aos seus antigos proprietários, fato que faculta seu uso por todos. Não se sabe os limites do Parque que só existe no papel. Para o ano de 2007 ocorreu um incêndio de grandes proporções na área do parque. Segundo cálculos aproximados, cerca de $12 \mathrm{~km}^{2}$ foram atingidos pelo fogo (Santos, 2007). Foi identificada ainda uma UC de Uso Sustentável onde, segundo a Lei, o uso sustentável é permitido. Esta UC é representada por uma Área de Proteção Ambiental (APA). Identificou-se também uma Reserva Particular do Patrimônio Nacional $(\mathrm{RPPN})^{7}$ Pontal do Jaburu, preservada pelo proprietário e ainda UC Florestas Estaduais, que são fragmentos vegetacionais destinados a preservação da fauna e flora.

7 A RPPN não pôde ser mapeada como polígono devido à ausência de memorial que demonstrasse seus limites dentro da área de pesquisa (IBAMA, 2007). Sua indicação na fig. 4 se deu de forma pontual. 
Santos (2007) indicou a área da RPPN Pontal do Jaburu como a mais adequada para a reprodução e conservação do peixe Pirarucu. Esta área apresenta-se altamente preservada, inclusive com a presença dos maiores jacarés do Rio Araguaia. O proprietário destinou fiscalização particular, pelo que a entrada, inclusive para pesquisa, só é permitida com sua autorização.

\section{CONSIDERAÇÕES FINAIS}

Deve-se deixar claro que os recursos naturais são dádivas ao homem, pelo que utilizar subterfúgios políticos para contornar a legislação e destruir recursos naturais, que são de todos, e de um modo que em nada contribui para a coletividade, é algo inaceitável. Não foi objetivo da pesquisa o preservacionismo ambientalista intolerante ao desenvolvimento econômico, mas é preciso repensar os usos que se fazem da paisagem. O estado de Goiás e o Brasil não sofreriam dano algum se a região de estudo, com toda sua singularidade, fosse preservada na sua totalidade.

O Estado, que deveria assumir o papel de mediador entre os diversos atores envolvidos nos conflitos de uso da terra na área de estudo, se omite na fiscalização e aplicação das Leis Ambientais e aqueles que detêm o poder e influência política forçam a opinião dos menos favorecidos. Convencem-nos de que suas ações são benéficas; no entanto, e conforme a análise apresentada, todas as obras empreendidas na área de estudo mais agridem do que contribuem para o desenvolvimento econômico do povo ribeirinho, que na maioria continua marginalizado.

$\mathrm{O}$ discurso de que os empresários que extraem riquezas da área contribuem para a oferta de novos postos de trabalho não convence, já que suas atividades pouco empregam mão-de-obra humana. O boi, por exemplo, criado à solta, dispensa grandes cuidados e nas grandes fazendas encontram-se poucos funcionários.

O ribeirinho que depende do Rio Araguaia compreende que a preservação deste rio é mais rentável, mas a exploração através da pesca garante sua sobrevivência. Sendo assim, acredita-se que o aproveitamento da área para turismo de contemplação poderá gerar mais renda do que a agropecuária, que tem custos financeiros elevados. No entanto, é preciso resgatar o conceito de turista, já que muitas pessoas que se deslocam até o Rio Araguaia são apenas pescadores contrabandistas.

Quando da visita a campo identificaram-se dois exemplos positivos de práticas de turismo de contemplação: uma trilha ecológica, onde o turista percorre alguns poucos quilômetros no interior da floresta e, também, uma reserva particular onde a exuberância dos animais, principalmente do Jacaré-açu, um animal pouco visto no Rio Araguaia, indicava que por ali não havia caçadores. Há também iniciativas da comunidade local em produzir, artesanalmente, alimentos a partir de frutos típicos da região. No entanto, o Estado que apóia incondicionalmente o grande empresário não se solidariza com o ribeirinho, que muitas vezes se frusta nas suas iniciativas e voltam a pesca predatória.

Numa visão geral observou o predomínio da pecuária na porção norte e agricultura na porção sul. Os resultados indicaram também que o desmatamento não é contínuo, mas não menos agressivo, pois muitos lagos que se encontram dispersos na planície de inundação já se encontram atingidos pela falta de vegetação ciliar, que serve de proteção aos lagos e a fauna. Mesmo que aparentemente preservada, as florestas apresentam usos no seu interior, especialmente para pecuária, pois o gado bovino circula livremente pela área. 
Quanto a metodologia conclui-se que os dados de sensoriamento remoto provenientes do satélite CBERS-2 apresentaram alto grau de detalhe da paisagem, configurando elemento importante para o tipo de estudo realizado, mas que por si só não sustentou a análise que foi contemplada com o trabalho de campo.

Acredita-se que a pesquisa apresentou um esforço para o estudo da paisagem da zona úmida do rio Araguaia, revelando usos e implicações sócio-ambientais, mas que não esgotou as possibilidades de análise. São necessários estudos sobre a fauna, para que se possa identificar o grau de comprometimento deste elemento da paisagem. É também necessário um esforço maior no sentido de analisar o impacto causado pela pecuária nos mais de 500 ambientes lacustres encontrados na zona úmida.

\section{BIBLIOGRAFIA}

Arruda A C (2007) Chuva põe Araguaia em sinal de alerta. O Popular, 15(1): 2.

Brasil (2006) Plano nacional de recursos hídricos. MMA, Brasília.

Castro S S (2005) Erosão hídrica na alta bacia do rio Araguaia: distribuição, condicionantes, origem e dinâmica atual. Revista Geografia, 17(1): 38-60.

IBAMA (2007) Lista de reservas particulares do patrimônio nacional. Brasília.

IBGE (2007) Estatísticas gerais do Brasil. Brasília.

IBGE (2006) Manual técnico de uso da terra. Rio de Janeiro.

IPEA (2007) Estatísticas Econômicas do Brasil. Brasília.

INPE (2007) Imagens CBERS. [Acedido em 13 de Setembro de 2007]. http://www.cbers.inpe.br/pt/ index_pt.htm

Leobas C (2002) Operação de guerra contra MST em Goiás. O Popular, 8(2): 3-4.

Lima J E F W, Santos P M C, Carvalho N O, Silva E M (2003) Fluxo de sedimentos em suspensão na bacia do Araguaia-Tocantins. Embrapa Cerrado, Brasil.

Morais R P (2006) A planície aluvial do médio rio Araguaia: processos geomorfológicos e suas implicações ambientais. Dissertação de doutorado, Universidade Federal de Goiás, Goiânia.

Moreira M (2001) Fundamentos do sensoriamento remoto e metodologias de aplicação. Inpe, São José dos Campos.

Pereira R (1976) Peixes de nossa terra. Nobel, São Paulo.

Santos A M (2007) Análise da paisagem dos lagos na região de Luiz Alves (Médio Araguaia) aplicada à preservação do Pirarucu (Arapaima gigas) a partir de métodos indiretos - sensoriamento remoto. Dissertação de mestrado, Universidade Federal de Goiás, Goiânia.

Santos A M, Romão P A (2007) Estudo multitemporal e alteração na paisagem na região do distrito de Luiz Alves, município de São Miguel do Araguaia-GO, a partir de método indireto, sensoriamento remoto. Geografia, 16(2): 85-112.

SEPLAN (2007) Estatísticas de Goiás. Goiânia. http://www.seplan.go.gov.br/sepin/ [Acedido em 17 de Setembro de 2007].

Souza F C, Almeida M G (2002) Turismo no Araguaia. Encontro Nacional de Geógrafos. João Pessoa.

Sgrecia F A (2006) Contos e causos do Rio Araguaia. Edição Independente, Goiânia.

WWF-Brasil (1996) Admiráveis áreas úmidas. Banson, Londres. 